\title{
Analysis of the impact of road transport emissions into the atmosphere on the example of Russia
}

\author{
Diana Lotnikova ${ }^{1 *}$ and Vladimir Nagorny ${ }^{1}$ \\ ${ }^{1}$ Kuban State Technological University, 2 Moskovskaya str., Krasnodar, 350072, Russian Federation
}

\begin{abstract}
Emissions of pollutants into the atmosphere in Russian cities in 2000-2020 from stationary sources decreased slightly, but emissions from mobile sources increased. Premature mortality from chemical air pollution alone is estimated, at 40-80 thousand people per year. The increase in air pollution by motor vehicles, due to the growth of road transport and the fleet of cars. There is no significant transition to environmentally friendly transport. The health impact of high levels of urban population, premature deaths per year, and economic damage of over $8 \%$ of GDP. There is an increase in air pollution by motor vehicles, due to the growth of road transport and the fleet of cars. In recent years, the global energy markets have seen a decline in the growth of demand for hydrocarbons. This is largely due to the long-term trend towards decarbonization, which involves the introduction of energy-efficient technologies, the spread of the price of carbon, and the accelerated development of low-carbon and carbon-free energy sources. To reduce the risks of carbon regulation, as well as to realize new opportunities, it is necessary to create an effective national strategy for low-carbon development of Russia and an effective system of carbon regulation.
\end{abstract}

\section{Introduction}

The automobile and road complex of the city and the environment. A city is a set of processes and phenomena that characterize the specific way of life of large masses of people in an anthropogenic ecological environment and a high concentration of population and production. Considering the problems of modern cities, UNESCO came to the conclusion in 1972 that "the city, having previously been the center of influence of civilization, is now considered as a source of any form of pollution".

\section{Materials and methods}

One of the main pollutants (in addition to industry, transport, energy and utilities) of the urban environment is the automobile and road complex (ADC). The automobile and road complex includes vehicles (cars and trucks, buses), road infrastructure, street network, road

\footnotetext{
* Corresponding author: diana.lotnikova@gmail.com
} 
construction equipment, service enterprises, engineering equipment of streets and roads for traffic management. According to MADI research, the volume of environmental pollution by transport is $60.6 \%$, industry $16.8 \%$, enterprises that generate electricity-14.1, heating-5.0, waste disposal-3.5. And if we consider the types of transport, the share of automobile falls $70 \%$, transport noise falls to $60-80 \%$ of the noise that overtakes a person in residential buildings [1]. Vibration accumulates defects in buildings and structures. Their precipitation in the conditions of city Krasnodar reaches up to $2.5 \mathrm{~mm}$ per year. The noise level from cars and trucks reaches $86 \mathrm{dBA}$, and from construction equipment up to-105 dBA. It is known, that without any special consequences, a person can tolerate noise only up to $40 \mathrm{dBA}$. The air of modern cities and the primagistral territory is oversaturated with lead, which is formed as a result of the combustion of leaded gasoline. Increased lead content is observed in the main-line territories of the Krasnodar Territory. Transport highways of the city with heavy traffic contain up to $154 \mathrm{mg} / \mathrm{kg}$, yard areas- $224 \mathrm{mg} / \mathrm{kg}$. Lead is found at depths of up to 120 $140 \mathrm{~cm}$. The content of petroleum products in the soils of transport highways is 6-30 times higher than in the soils of parks, gardens, and squares [2].

All pollutants of the natural environment of the city from the automobile and road complex can be divided into two groups:

- chemical, toxic exhausts of vehicles, road construction machines; machines used in the operation of urban roads (oxides of carbon, nitrogen, sulfur, carbon, formaldehyde, soot, lead, cadmium, and for diesel engines - nitrosodialkylamines); products of abrasion of tires, cement, asphalt concrete coatings (heavy metals, 3,4-gasoline-a-pyrene); abrasion of transmissions, brake systems (asbestos), petroleum products;

- physical, noise, vibration, electromagnetic fields; radioactivity and toxicity of road construction materials of natural and man-made origin [3].

According to the degree of exposure to humans, toxicants belong to different hazard classes, for example, benzapyrene, lead - to the 1st hazard class, cause cancer. When considering the issue of urban pollution, we usually talk about the pollution of the city's air basin (at the same time, as already mentioned, about $70 \%$ of harmful substances are accounted for by motor transport, which emits about 170 thousand tons of toxicants per year and this number is growing annually).

It is known that the amount of environmental pollution in large cities depends on the following factors:

- from the design of cars - by $30 \%$;

- from their technical condition during operation - by $30 \%$;

- from the condition of the road surface and the organization of traffic - by $40 \%$;

\section{Conclusion}

The automobile and road complex pollutes not only the air environment, but also water bodies, waste water, urban land (soil). At the same time, the trend is that urban areas will expand, the number of floors of construction will increase, and the traffic intensity will increase along the increasing areas of streets and city roads. All this worsens the state of the urban environment and living conditions of citizens, increases the growth of diseases. In the context of the decarbonization of the world economy, Russia, as a country specializing in the production and export of hydrocarbons, metals, fertilizers and other products with a high carbon footprint, faces a number of long-term development risks. To reduce the risks of carbon regulation, as well as to realize new opportunities, it is necessary to create an effective national strategy for low-carbon development of Russia and an effective system of carbon regulation. Opportunities to mitigate these and other risks, as well as to realize new opportunities that open up in a number of technological niches, lie in the formation of a national low-carbon strategy, the key elements of which can be: tightening the national goal 
to reduce emissions and link it to the economic dynamics in the country, the formation of a national system for reporting, monitoring and economic regulation of greenhouse gas emissions, the development of national registers and regulatory institutions for green finance, integration of Russian legislation with common international practices of green finance and low-carbon reporting.

\section{Environmental situation in Russian cities}

Emissions of pollutants into the atmosphere in Russian cities in 2000-2020 from stationary sources decreased slightly, but emissions from mobile sources increased. Pollution remains high, including substances that are dangerous to public health. Discharges of polluted water generally tend to decrease, but the volume of discharges of hazardous substances remains large and even increases. Premature mortality from chemical air pollution alone is estimated at 40-80 thousand people per year [4,5].

Air pollution in Russian cities remains dangerous. There is an increase in air pollution by motor vehicles, due to the growth of road transport and the fleet of cars. There is no significant transition to environmentally friendly transport. With the reduction of gross emissions of pollutants from stationary sources in many cities, the level of pollution remains dangerous or extremely dangerous. Exposure to high levels of CO, PM10, SOx, and other substances in water, air, and soil results in more than 104,000 deaths in urban areas. premature deaths per year and damage to the economy in excess of $8 \%$ of GDP [World Bank, The Cost of Air Pollution, 2016].

The combination of air pollution and heat in cities leads to additional deaths. In 2010, 54,000 people died from heat waves in the European part of the Russian Federation [B. A. Revich, Heat waves as a risk factor for public health // Pulmonology, No. 4, 2011].

Risks, consequences if the situation continues this:

- Increased damage from environmental pollution, risks to public health;

- Aggravation of problems with waste disposal, growth of social protests;

- Decline in the quality of life, habitat, and attractiveness of cities (migration of the economically active population from large industrial centers).

Measures that we can take to improve the situation: The introduction of effective systems for monitoring the quality of atmospheric air, water, and soil in cities. Mandatory implementation of automatic continuous monitoring systems for waste gases at industrial enterprises and power facilities. Creating incentives and mechanisms for managing water, air, soil, and waste pollution at all stages of the life cycle (prevention, disposal, and disposal). Implementation of water quality monitoring and management measures, construction of modern treatment facilities, development of sanitary and technical sewerage infrastructure [6].

According to the forecasts of the Ministry of Economic Development, an increase in environmental protection spending to $1.5 \%$ of GDP in the period $2020-2030$ will reduce the specific indicators of negative environmental impact by an average of 3 times by 2030 . The national project "Ecology" provides for: elimination of the most dangerous objects of accumulated environmental damage and environmental improvement of water bodies (Volga, Baikal, Teletskoye); reducing the emissions of hazardous pollutants that have the greatest negative impact on the environment and human health by two times; creating a sustainable solid municipal waste management system that ensures waste sorting in the amount of $100 \%$ and reducing the volume of waste sent to landfills by two times The State program of the Russian Federation "Environmental Protection" assumes until 2024: the elimination of 75 of the most dangerous objects of accumulated environmental damage, reducing the total amount of emissions into the atmosphere by $22 \%$, and in the years In Nizhny Tagil, Novokuznetsk, Chita, Bratsk, Krasnoyarsk, Chelyabinsk, Magnitogorsk and 
Norilsk, reducing the level of atmospheric air pollution (from high and very high levels), improving environmental conditions for 36.4 million Russians currently living in cities with high and very high levels of atmospheric air pollution [7].

In recent years, the global energy markets have seen a decline in the growth of demand for hydrocarbons. This is largely due to the long-term trend towards decarbonization, which involves the introduction of energy-efficient technologies, the spread of the price of carbon, and the accelerated development of low-carbon and carbon-free energy sources. This trend will continue with the peak consumption of coal in the first half of the 2020 s, oil in the 2030 s, and natural gas in the 2040s.

A slowdown in the growth of demand for hydrocarbon fuels. The slowdown in the growth of global demand for hydrocarbons is associated with long-term trends in improving the efficiency of energy use processes in all sectors of the economy. If in the 2000 s the demand for fossil fuels in the world grew at an average rate of $2.4 \%$ per year, then in the period 2020 2027 it will grow at a rate of 1-1. 5\% per year. The energy intensity of GDP in 2050 will be 10 times lower than in 2016. In the last ten years alone, the energy intensity of GDP has decreased by $9.4 \%$, reaching a level of 0.174 tons of oil equivalent per thousand US dollars. According to the IEA, in the scenario of a smooth exit from the crisis in the period from 2019-2030, the change in the share of coal in the structure of total demand will be $-4 \mathrm{p} . \mathrm{p}$. (from $26 \%$ to $24 \%$ ), oil --2 p. p. (from $32 \%$ to $30 \%$ ), and natural gas -+1 p. p. (from $23 \%$ to $24 \%$ ) $[8,9]$.

\section{Growing competition from carbon-free and low-carbon energy sources}

In the period 2019-2030, the share of renewable energy sources (RES) in the structure of energy consumption will increase by 5 percentage points (from $10 \%$ to $15 \%$ ). The role of renewable energy sources will increase most rapidly in the electric power industry according to the IEA forecasts, in the scenario of a smooth exit from the crisis, the share of renewable energy sources in electricity production will increase to $80 \%$ over the next decade, surpassing coal as the main fuel for electricity generation by 2025 .

Formation of a national strategy for low-carbon economic development and its fuel and energy complex, taking into account long-term trends in inter-fuel competition; formation of a system of economic incentives for the development of low-carbon energy sources, including through the launch of a national carbon regulation system and a set of other technological and industry measures - Implementation of a group of measures aimed at minimizing damage from external shocks and implementing a low-carbon strategy for vulnerable social groups and sectors of the economy, especially the coal industry [10].

Risks of a reduction in the volume of Russian hydrocarbon exports (see figure 1) and the loss of part of the income of Russian exporters and the Russian budget. The reorientation of global technological development towards low-carbon sectors of the economy and the risks of technological backwardness. Assets in the traditional energy sector are becoming less attractive to private investors, which risks losing the long-term sustainability of the model of economic development based on the use and export of fossil fuels. In some markets, there are additional opportunities to maintain a stable position (Germany) or increase exports (China) of natural gas, especially liquefied natural gas. Technological and production groundwork in nuclear and gas energy: it is possible to strengthen Russia's leading position in these and related areas, in particular, the commercialization and scaling of hydrogen fuel production technologies. 

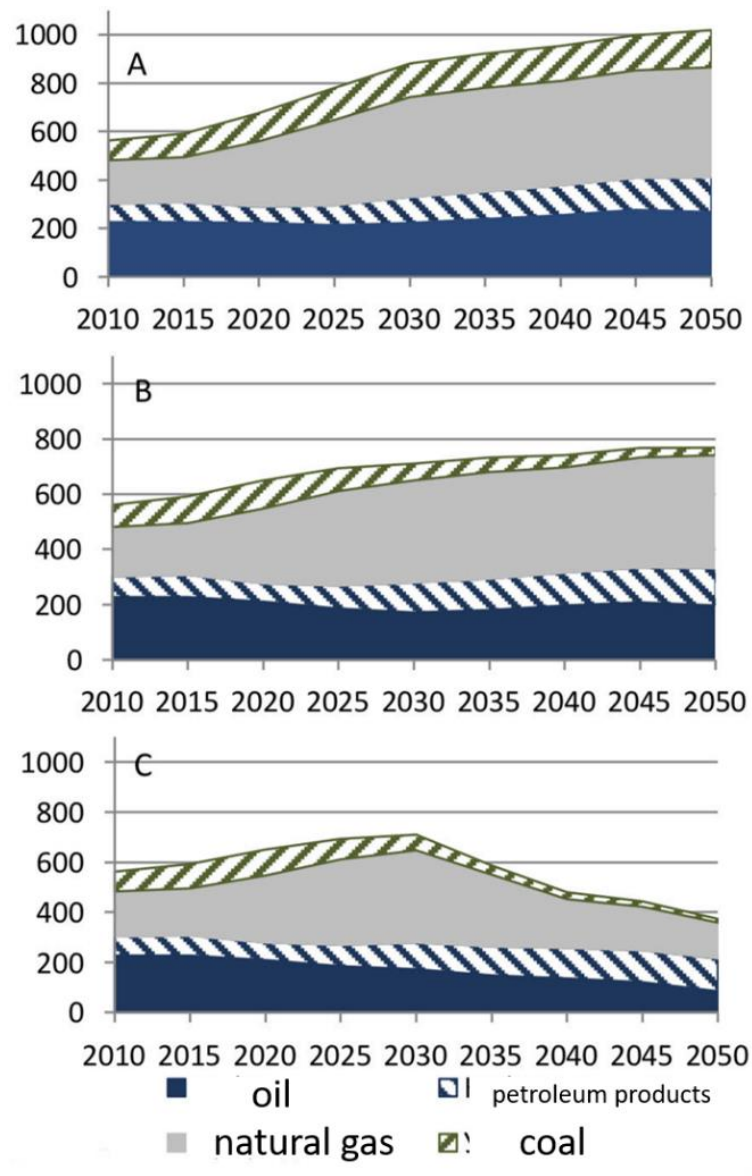

Fig. 1. Forecast of energy exports from Russia until 2050. in the basic forecast (A), forecast of implementation of INC (B), forecast "2 degrees" (C).

Schedule explanation - A. Baseline forecast - a forecast without any measures to reduce greenhouse gas emissions in the world - B. INDC forecast - all countries reduce greenhouse gas emissions in accordance with the nationally determined contributions (INDC) under the Paris Agreement for 2030, and do not make additional efforts after 2030 • B. "2 degrees" forecast - all countries reduce greenhouse gas emissions by 2050 based on the ultimate goal of the Paris Agreement - "keeping the Earth's temperature rise at no more than 2 degrees compared to the pre-industrial period.

The number of countries that have announced plans for full decarbonization in the coming decades is growing rapidly. Climate policy is becoming a key part of economic policy in the leading countries of the world. It serves both directly to reduce emissions and meet international obligations in this area, as well as to address a number of domestic economic, social and industry objectives-from improving energy efficiency to creating jobs and reducing the risks of increased competition in foreign markets [11].

Global economic growth continues to be accompanied by an increase in greenhouse gas emissions. Since the turn of the century, global GDP has grown by $41.2 \%$, while emissions have increased by $30.7 \%$. Economic growth and wealth growth are still closely linked to the speed of industrialization, especially in developing countries. At the same time, a growing 
number of countries are seeing an increase in climate policy. In addition to the direct risks associated with climate change, the desire to increase energy efficiency, strengthen energy security, create new jobs, provide technological leadership, and solve the problem of local air pollution is an incentive to increase the ambition of climate policy.

\section{Risks and opportunities}

- Risks of loss of competitiveness of Russian exporters of hydrocarbons and carbon-intensive goods;

- Risks of protectionist measures in trade on the part of importers of Russian products with a high carbon footprint (primarily the EU);

- While maintaining the status quo in Russia's climate policy-risks of technological backwardness in low-carbon sectors of the economy;

- The implementation of an active low-carbon strategy will help mitigate the abovementioned risks, as well as solve a number of parallel tasks, including improving energy efficiency, creating jobs, developing new sectors of the low-carbon high-tech economy, etc.

\section{Recommendations}

- Tightening the current national target for reducing greenhouse gas emissions ( $70 \%$ of 1990 levels by 2030).)

- Formation of a national system for monitoring, reporting and verifying emissions reductions, launch of a national system for regulating greenhouse gas emissions

- Strengthening of state programs for improving energy efficiency and developing renewable energy sources

- A set of measures to diversify the economy and reduce its dependence on fossil fuels.

Introduction of a carbon tax and other measures to combat greenhouse gas emissions. Economic regulation of greenhouse gas emissions is becoming increasingly widespread in both developed and developing countries. The tightening of national emission controls reduces the competitiveness of national businesses, which encourages the introduction of borderline carbon regulations aimed at products from countries that do not regulate greenhouse gas emissions.

The spread of the carbon price as a public policy tool in many countries. Many countries are implementing economic regulation of greenhouse gas emissions-through a carbon tax or an emissions trading system (ETS), or hybrid instruments that combine elements of both. Economic regulation of emissions plays a special role in the EU, where 16 countries have introduced carbon taxes and the most developed European ETS, launched in 2005. At the moment, the EU ETSC covers more than 11 thousand enterprises in 31 countries. The system covers the heat and power generation sector, energy-intensive production, including oil refining, metallurgy, cement and chemical industries, wood processing, glass and ceramic industries, and also extends to the commercial aviation sector. One of the options for developing the system in the coming years is to include foreign exporters of products in these industries. Today, there are about 70 national and subnational systems of economic regulation of emissions, and their number continues to grow. In addition to European countries, markets for trading in emissions permits and carbon taxes operate in most of the leading economies, including Japan, South Korea, California, Canada, Australia, and others.

The tightening of climate policy in the importing countries of Russian products (primarily in the EU, but further in other countries) creates risks of reducing demand for Russian exports of carbon-intensive products and is fraught with significant financial losses. 
Formation of a national system for monitoring, reporting, and verifying emissions and the creation of a system of carbon regulation in Russia that takes into account the specifics of the Russian economy and possible social consequences. Intensification of the negotiation process with European partners to coordinate the process of introducing carbon trade barriers, and in the future-the integration of the EU and Russian carbon regulatory systems.

The risks of weakening the competitiveness of national producers in comparison with producers of products from countries with relatively more lenient climate laws are pushing the country's leadership to increasingly discuss the possibility of introducing border carbon barriers aimed at protecting the competitiveness of national businesses. According to the EU's plans, Carbon Border Adjustment Mechanism will be introduced no later than 2023.* Among the largest countries, Russia ranks first in terms of specific greenhouse gas emissions in the composition of exported products (necessary for the production of products sent for export), and Russian exporters of carbon-intensive products (producers of metallurgical, chemical and petrochemical products) are most vulnerable to carbon border barriers. Possible losses from the introduction of border carbon barriers in the EU will range from $\$ 80$ million to $\$ 1.24$ billion per year (see figure 2 ).

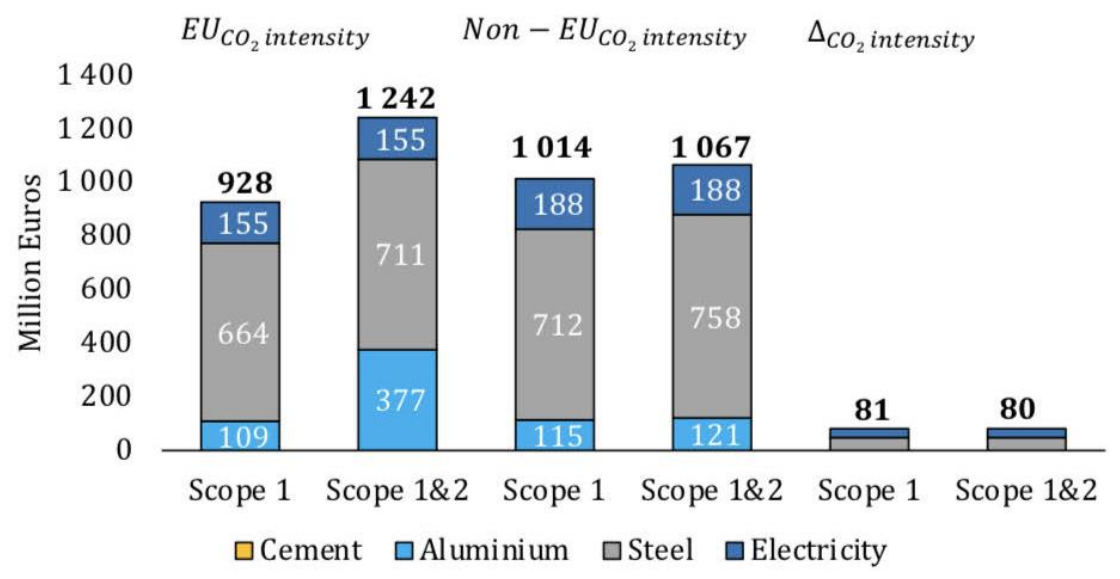

Fig. 2. Estimates of losses of Russian exporters in three scenarios of the introduction of border carbon regulation in the EU. Source: ERNST, 2021.

\section{References}

1. D.Yu. Lotnikova, V.V. Nagorny, Problems of functioning of transport systems of Russia in the collection: Problems of functioning of transport systems. Materials of the All-Russian (National) scientific and Practical Conference of Students, postgraduates and Young Scientists. Federal State Budgetary Educational Institution of Higher Education "Tyumen Industrial University". 2020, p. 412-413 (2020)

2. A.B. Melnikov, I.V. Snimschikova, E.I. Artemova, The world Economy : textbook (Publisher GKAU Krasnodar, 2009)

3. A.B. Melnikov, E.I. Artemova, I.A. Bursa, B.A. Melnikov, Humanities, socioeconomic and social sciences 3, 189-194 (2012)

4. T.V. Konovalova, S.L. Nadiryan, M.P. Mironova, Yu.P. Mironova, Nauka, Tekhnika, Tekhnologii (politechnicheskiy vestnik) 4, 89-93 (2015) 
5. V.V. Nagorny, In the collection: mechanics, equipment, materials and technologies. Electronic collection of scientific articles based on the materials of the third scientific and practical Conference 2020, pp. 1160-1163 (2020)

6. D.Yu. Lotnikova, In the collection: mechanics, equipment, materials and technologies. Electronic collection of scientific articles based on the materials of the third scientific and practical conference 2020, p. 1139-1141 (2020)

7. R. Solow, Growth Theory: An Exposition (Robert Solow-Oxford: Oxford University Press, 2000)

8. T.V. Konovalova, S.L. Nadiryan, Nauchnye trudy Kubanskogo gosudarstvennogo tekhnologicheskogo universiteta 4, 431-441 (2015)

9. Ukaz Prezidenta RF ot 19 aprelya 2017 g. № 176 «O Strategii ekologicheskoy bezopasnosti Rossiyskoy Federatsii na period do 2025 goda». URL: http://www.consultant.ru/document/cons_doc_LAW_215668/.

10. A.I. Altukhov, A.N. Anishchenko, E.I. Artemova, et al, Strategy for the development of the agricultural sector of the economy: problems and solutions (Krasnodar, 2017)

11. D.V. Shiryaev, E.I. Artemova, M.V. Zelinskaya, S.N. Novoselov, S.D. Galiullina, E.E. Pismennaya, International Review of Management and Marketing 6, S1, 232-237 (2016) 